\title{
Aortoesophageal Fistula of Unusual Location
}

We report a case of aortoesophageal fistula, which presented as a bleeding esophageal tumor located just above the cardia.A 69year-old man was admitted to the emergency department after an episode of melena. He was suffering from hyperlipidemia, hyperuricemia, and hypertension. There had been no recent gastrointestinal symptoms or ingestion of nonsteroidal antiinflammatory drugs. He was pale, but the heart rate and blood pressure were normal. Hemoglobin was $9.0 \mathrm{~g} / \mathrm{dl}$. The endoscopic examination showed a $5-\mathrm{cm}$ long ovoid tumor in the esophagus near the cardia, with a central ulceration occupied by a fresh blood clot (Figure 1). We considered a diagnosis of ulcerated leiomyoma, or an extraesophageal lesion involving the esophageal wall. No endoscopic therapy was carried out, and the patient's condition remained stable. He died after an exsanguinating hematemesis on the sixth day. The autopsy revealed an aortic atherosclerotic aneurysm, leaking into the distal esophagus through a hematoma in the esophageal wall (Figure 2).

Aortoesophageal fistulas are a rare cause of gastrointestina bleeding. Almost half of the cases are due to atherosclerosis of the aorta. Clinically, they are characterized by Chiari's triad: thoracic pain, sentinel hemorrhage, and massive bleeding after a free interval. Dysphagia may be present $(1,2)$. Endoscopy has been shown to be safe and valuable. The typical presentation is of a tumor or intramural mass in the mid-esophagus, either bleeding or

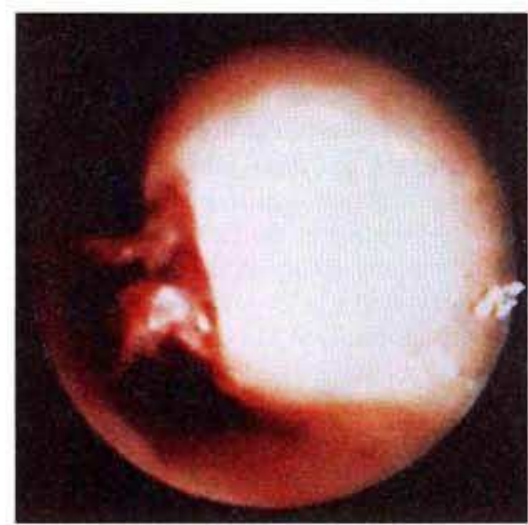

Figure 1: Endoscopic presentation of the aortoesophageal fistula, simulating an esophageal tumor.

with an adherent clot $(1,2)$. In spite of the high mortality rate associated with the condition, some patients have survived after emergency surgery. Tamponade with a Sengstaken-Blakemore tube can be effective, although it is a provisional measure until surgery can be carried out $(1-4)$. The present case featured some unusual aspects that were misleading in the diagnosis: no thoracic pain or dysphagia, and the location of the fistula just above the cardia. 


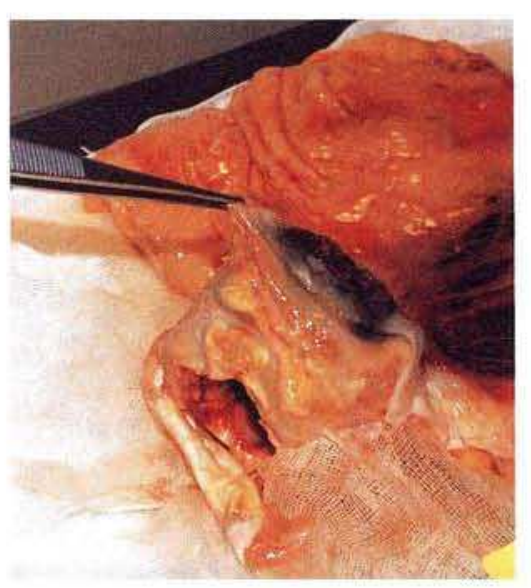

Postmortem examination of the aneurysm, showing the aorta and the large hematoma protruding into the distal esophagus.

J. da Fonseca ', F. Gonçalves', J. Freitas ', P. Borralho ${ }^{3}$, C. Leal ${ }^{\prime}$ ${ }^{1}$ Division of Gastroenterology

${ }^{2}$ Dept. of Internal Medicine

${ }^{3}$ Dept. of Pathology, Garcia de Orta Hospital, Almada, Portugal

\section{References}

1. Sosnowik D, Geenberg R, Bank S, Graver LM. Aortoesophageal fistula: early and late endoscopic features. Am J Gastroenterol 1988; 83: 1401-4.

2. Hollander JE, Quick G. Aortoesophageal fistula: a comprehensive review of the literature. Am J Med 1991; 91: 279-87.

3. Peck JJ, Eidemiller LR. Aortoenteric fistulas. Arch Surg 1992; 127: 1191-3; discussion, 1193-4.

4. Von Oppel UO, de Groot M, Thierfelder C, Zilla P, Odell JA. Successful management of aortoesophageal fistula due to thoracic aortic aneurysm. Ann Thorac Surg 1991; 152: 1168 70 .

Corresponding Author

J. da Fonesca M.D.

Serviçio de Gastroenterologia

Hospital Garcia de orta

2800 Almada

Portugal 